\title{
Öğretmen Adaylarının Kendini Belirleme (Güvengenlik) Düzeylerinin Çeşitli Değişkenler Açısından İncelenmesi *
}

\section{Teacher Candidates' Assertiveness Levels in terms of Different Variables}

\section{Fatma Betül ŞENOL ${ }^{* *}$}

Received: 31 May 2018

\author{
Tuğçe AKYOL ${ }^{* * *}$
}

\section{Münevver CAN-YAŞAR ${ }^{* * * *}$}

\begin{abstract}
This study was conducted to examine and determine if teacher candidates' assertiveness levels differ in terms of their moods, gender, age, department, family type, birth order and perceived communication level with their friends. The study sample consisted of $4654^{\text {th }}$ year classroom teacher candidates attending Afyon Kocatepe University, Education Faculty in the 2017-2018 academic years. The data collection instruments of the study were the Personal Information Form designed to get information about the participant teacher candidates, the Voltan Acar Assertiveness Scale (Voltan Acar \& Öğretmen, 2007) administered to assertiveness levels of the participant teacher candidates and the Facial Expressions Form (Thayer \& Schiff, 1969) so as to specify the participant teacher candidates' moods. Considering the results of Kolmogorov-Smirnoff normality test, the data which displayed a normal range was analyzed with independent samples t-test and One Way Anova was used. For the groups that did not display a normal range, Mann Whitney $\mathrm{U}$ and Kruskal Wallis H Test were used. To the study results, there was a meaningful difference between teacher candidates' assertiveness levels and their ages, departments, family types, communication styles and moods; no statistically significant difference was found between their assertiveness levels and their genders and birth orders.
\end{abstract}

Keywords: teacher candidates, assertiveness, mood.

ÖZ: Bu araştırma, öğretmen adaylarının güvengenlik düzeylerinin; duygu durumları, cinsiyet, yaş, bölüm, aile tipi, doğum sırası, arkadaşları ile algıladıkları iletişim düzeylerine göre, farklılık gösterip göstermediğini incelemek amacıyla gerçekleştirilmiştir. Araştırmanın çalışma grubunu, 2017-2018 eğitim öğretim yılında Afyon Kocatepe Üniversitesi Eğitim Fakültesinde öğrenim gören toplam 465 dördüncü sınıf öğretmen adayı oluşturmaktadır. Araştırmada veri toplama aracı olarak, öğretmen adayları ile ilgili bilgi almak amacıyla Kişisel Bilgi Formu, öğretmen adaylarının güvengenlik düzeylerini belirlemek amacıyla Voltan Acar Kendini Belirleme Envanteri (Voltan Acar \& Öğretmen, 2007) öğretmen adaylarının duygu durumlarını belirlemek için ise Yüz İfadeleri Formu (Thayer \& Schiff, 1969) kullanılmıştır. Elde edilen verilerin analizinde; Kolmogorov-Smirnoff (K-S) normallik testi sonucunda, normal dağılım gösteren gruplarda, gruplar arası farklılık incelenirken bağımsız örneklemler t testi ve Tek Faktörlü Anova, normal dağılım göstermeyen gruplarda ise, gruplar arası farklılık incelenirken Mann Whitney U ve Kruskal Wallis H Testi kullanılmıştır. Araştırma sonucunda, öğretmen adaylarının güvenlik düzeyleri ile yaşları, öğretmenlik alanları, aile tipleri, iletişim türleri ve duygu durumları ile anlamlı bir farklılık olduğu; güvengenlik düzeyleri ile cinsiyetleri ve doğum sıraları arasında anlamlı farklılık olmadığı sonucuna ulaşılmıştır.

Anahtar Kelimeler: öğretmen adayları, güvengenlik, duygu durumları.

\footnotetext{
* This study was presented at "International Congress on Science and Education-2018" as an oral presentation.

** Corresponding Author: Res. Asst. Dr., Afyon Kocatepe University, Afyonkarahisar, Turkey, betululu@aku.edu.tr

**** Asst. Prof. Dr., Afyon Kocatepe University, Afyonkarahisar, Turkey, akyol.tugce@ gmail.com

***** Assoc. Prof. Dr., Afyon Kocatepe University, Afyonkarahisar, Turkey, munevver2002@gmail.com
}

\section{Citation Information}

Şenol, F. B., Akyol, T., \& Can-Yaşar, M. (2018). Öğretmen adaylarının kendini belirleme (güvengenlik) düzeylerinin çeşitli değişkenler açısından incelenmesi. Kuramsal Eğitimbilim Dergisi [Journal of Theoretical Educational Science], UBEK-2018, 146-165. 


\section{Giriş}

Eğitimin temel amaçlarından biri, bireylerin farklı durumlara kolaylıkla adapte olabilmelerini sağlamak ve bireylere eleştirel düşünme becerilerini kazandırır. Bu amaçların gerçekleştirilebilmesi için toplumsal açıdan önemli bir role sahip öğretmenlerin çocuklar, meslektaşları ve aileler ile olumlu ilişkiler kurmaları önemlidir. Öğretmenlerin başkaları ile etkileşim kurabilmeleri için sosyal açıdan kabul edilebilir davranışlar olarak tanımlanan sosyal becerilere sahip olmaları gerekir (Yüksel, 2001). Sosyal beceriler bireylerin iletişim kurmasını kolaylaştırdığ için insanların yaşamında oldukça önemli bir role sahiptir (Avcıoğlu, 2007; Elliason \& Jenkins, 2008). Sosyal becerileri yeterli düzeyde olan bireyler, kendilerini rahatlıkla ifade edebilirler, karşısındakini anlayabilirler ve başkaları tarafından olumlu bir şekilde algılanmak isterler (Segrin, 2001). Calderalla ve Merrell (1997) sosyal becerileri sınıflandırırken, güvengenlik becerilerinin sosyal becerilerin boyutlarından biri olduğunu belirtmişlerdir. Birey güvengen olduğunda, doğru zamanda gerekli sosyal davranışı sergilemiş olur (Martínez, Justicia \& Haro, 2016). Kişiler arası ilişkilerin niteliğinin geliştirilmesi için güvengenliğin sosyal beceriler kapsamında değerlendirilmesi gereklidir (Güneş, Arslan, \& Eliüşük, 2016; Voltan, 1980).

Güvengenlik kavramı, 20. yüzyılın ortalarında Amerika'da "assertiveness" adıyla bir davranış örüntüsü olarak tanımlanmış ve 1970'li yılların sonunda Türkçede bu kavramın karşıllğı "güvengenlik" olarak kabul edilmiştir (Voltan, 1995). Alanyazında atılganlık ve güvengenlik kavramlarının birbirlerinin yerine kullanıldığı görülmekle birlikte bu araştırmada "assertiveness" kavramı çalışma kapsamında kullanılan "Kendini Belirleme (Güvengenlik) Ölçeğii”nde de belirtilen "güvengenlik" kavramı olarak kullanılacaktır. Güvengenlik, bireylerin başkalarının haklarını da gözeterek kendi haklarını gözetebilmeleri şeklinde ifade edilmektedir (Alberti \& Emmos, 1998). Güvengenlik, sosyal etkileşimler sırasında kendini ifade edebilme becerileri olarak da tanımlanmaktadır (Vagos \& Pereira, 2010). Güvengenlik, kişilerin sahip olduğu iki uçtaki çekingen ve saldırgan davranışların uzlaştığı bir denge noktasidır (Voltan, 1980). Alberti ve Emmons (2002) güvengen bireylerin, olumlu ve olumsuz duygularını rahatlıkla ifade edebildiklerini, onaylamadıkları istekleri geri çevirebildiklerini ve karşısındaki bireylerden istekte bulunabildiklerini belirtmişlerdir. $\mathrm{Bu}$ açıdan bakıldığında güvengen bireylerin kişilerarası ilişkilerde eşitliğe önem verdikleri ve topluma sağlıklı bir şekilde uyum sağladıkları düşünülebilir (Voltan Acar, Arıcıoğlu, Gültekin \& Gençtanırım, 2008).

Güvengenlik bireylerin duygusal iyi oluşluk düzeylerini etkileyen en önemli sosyal becerilerden biridir (Eskin, 2003). Güvengen olmak aynı zamanda bireylerin özgüvenlerinin artmasını ve başkalarının saygılarını kazanmalarını sağlar (Mayo Clinic Staff, 2012). Güvengenlik bireyin yaşamındaki stres faktörleriyle etkili bir şekilde baş edebilmesini sağlamaktadır. $\mathrm{Bu}$ durum yetişkinlerin özgüvenlerini arttırır, yaşam kaygılarını azaltır, iletişim biçimlerini çeşitlendirir ve tüm bunların sonucunda stresle baş etme becerilerini geliştirir (Vatankhah, Daryabari, Ghadami, \& Naderifar, 2013). Genç yetişkin olarak nitelendirilen üniversite öğrencilerinin mesleki bilgi ve becerilerini iyi bir şekilde sergileyebilmeleri ve etkili iletişim kurabilmeleri için güvengenlik düzeylerinin yüksek olması gerekir (Karagözoğlu, Kahve, Koç, \& Adamişoğlu, 2008). Özellikle iletişim becerilerinin etkin bir şekilde kullanılması gereken meslekler için lisans eğitimi programlarında güvengenlik eğitimine yer verilmesi önemlidir (Niusha, 
Farghadani, \& Safari, 2012). Literatürde etkili iletişim becerilerine sahip olması gereken öğretmenlere lisans eğitimi sırasında verilen güvengenlik eğitimlerinin etkisini inceleyen çalışmalar vardır. Gündoğdu (2012) drama temelli atılganlık eğitimi programlarının Psikolojik Danışmanlık ve Rehberlik eğitimi öğrencilerinin güvengenlik becerileri üzerindeki etkisini incelediği araştırmada, deney grubunu oluşturan öğrencilere on hafta boyunca verilen eğitim sonrasında güvengenlik düzeylerinde artış olduğunu belirtmiştir. Güneş, Arslan ve Eliüşük (2016) atılganlık/güvengenlik eğitiminin eğitim fakültesi öğrencilerinin güvengenlik, kişiler arası problem çözme ve algılanan sosyal destek düzeyleri üzerindeki etkisini belirlemek amacıyla yaptıkları deneysel çalışmada, öğretmen adaylarına dokuz hafta boyunca verilen eğitimin güvengenlik, kişiler arası problem çözme ve algılanan sosyal destek düzeylerinin artmasında etkili olduğu sonucuna ulaşmışlardır.

Güvengenlik, eğitim süreçlerinde yer alması gereken, kişilerarası ilişkileri güçlendiren ve öğretmenlerin sahip olması gereken önemli mesleki niteliklerden biridir (Milovanoviç, Irkovi Miladınovıç, \& Stojanovi, 2016). Alanyazında öğretmen adaylarının güvengenlik düzeyleri ile iletişim becerileri (Küçükkaragöz, Canbulat, \& Akay, 2012; Haladin, Ibrahim, \& Rajab, 2013); problem çözme becerileri (Güven, 2010), sosyal destek algıları (Ateş, 2016), akademik başarıları (Dinçyürek, Güneyli \& Çağlar, 2012) ve öğrenme stilleri (Sucan, Turan, Pepe, Karaoğlu \& Doğan, 2016) arasındaki ilişkiyi ayrıca hemşirelik lisesi öğrencilerine uygulanmış grupla atılganlık eğimini (Voltan, 1980) inceleyen çalışmalar vardır.

Güvengenlik, etkili öğretim için önemli bir beceri olmasının yanısıra okul ortamında kişilerarası iletişim becerilerinin geliştirilmesine de katkı sağlar (Rusli, Nasir \& Hamzah, 2011). Öğretmenlerin öğrencileri ile etkili ve güvenli bir iletişim kurabilmeleri için güvengenlik becerilerini geliştirmeleri gerekir (Unal, 2012). Bu noktadan hareketle, bu araştırmada öğretmen adaylarının güvengenlik düzeylerinin o anki duygu durumları ve bazı demografik özellikler açısından incelenmesi amaçlanmıştır.

\section{Yöntem}

\section{Evren ve Örneklem}

$\mathrm{Bu}$ araştırma, öğretmen adaylarının güvengenlik düzeylerinin; duygu durumları (o anda kendilerini nasıl hissettikleri), cinsiyet, yaş, bölüm, aile tipi, doğum sırası, arkadaşları ile algıladıkları iletişim düzeylerine göre farklılık gösterip göstermediğini inceleyen betimsel nitelikte ve tarama modelinde bir çalışmadır.

Araştırma kapsamına giren bireyler 2017-2018 eğitim öğretim yılında Afyon Kocatepe Üniversitesi Eğitim Fakültesi'nde öğrenim gören toplam 465 dördüncü sınıf öğretmen adayından oluşmaktadır. Araştırmada ulaşabilme kolaylığı nedeniyle örneklem alma yoluna gidilmemiş, araştırmanın evreni çalışma grubu olarak kabul edilmiştir. Veriler 2017-2018 eğitim öğretim yılı güz döneminde toplanmış olup, veriler toplanmadan önce katılımcılara çalışma hakkında bilgi verilmiş ve katılımcıların sözlü onamları alınmıştır. Buna göre, araştırmanın çalışma grubunu oluşturan 465 öğretmen adayının, 126'sını Okul Öncesi Eğitimi, 63’ünü Sınıf Eğitimi, 59'unu Sosyal Bilgiler Eğitimi, 72'sini Türkçe Eğitimi, 78'ini Matematik Eğitimi ve 67'sini Fen Bilgisi Eğitimi son sınıf öğrencileri oluşturmuştur. 
Araştırmaya katılan öğretmen adaylarının demografik özellikleri incelendiğinde; \%80.2'sinin kadın, \%19.8'inin erkek olduğu; \%22.6'sının 20 yaş ve altında, $\% 38.7$ 'sinin 21 yaşında, \%26.5'inin 22 yaşında \%12.3'ünün 23 yaş ve üzerinde olduğu ve ancak \%19.4'ünün güvengenlik konusunda eğitim aldıkları belirlenmiştir.

\section{Veri Toplama Araçları}

Kişisel bilgi formu. Araştırmacılar tarafından geliştirilen form; öğretmen adaylarının cinsiyeti, yaşı, bölümü, mezun olduğu lise türü, aile tipi, kardeş sayısı, ailenin kaçıncı çocuğu olduğu, daha önce atılganlık eğitimi alma durumu, genel iletişim durumuna ilişkin çoktan seçmeli sorulardan oluşmaktadır.

Voltan Acar Kendini Belirleme (Güvengenlik) Envanteri (VAKBE). Voltan Acar ve Öğretmen (2007) tarafından üniversite öğrencilerinin güvengenlik düzeylerini belirlemek amacıyla geliştirilmiştir. Güvengen ve çekingen olmak üzere toplam iki boyuttan oluşan ölçek toplam 28 maddeden oluşmaktadır. 6'lı likert tipi olan ölçek "Beni hiç anlatmıyor" 1 ve "Beni çok iyi anlatıyor" 6 arasında puanlanmaktadır. Ölçekten en az 28, en çok 168 puan alınmakta ve ölçekten alınan puanlar arttıkça güvengenlik düzeyi de artmaktadır (Voltan Acar ve diğerleri, 2008). Ölçeğin orjinal iç tutarlılık güvenirlik katsayısı; güvengen boyutu için 0.78; çekingen boyutu için ise 0.83 ve toplam iç tutarlılık güvenirlik katsayısı 0.87 'dir. Bu çalışma kapsamında hesaplanan iç tutarlılık güvenirlik katsayısı güvengen boyutu için 0.78 , çekingen boyutu için 0.81 ve toplam 0.85 olarak bulunmuştur.

Yüz ifadeleri formu. Thayer ve Schiff (1969) tarafından geliştirilen Yüz İfadeleri Formu, 11 tane yüz ifadelerini içeren görsellerden oluşmaktadır. Yüz ifadeleri duygu durumlarını belirtmekte olup kafası karışı, ciddi, mutlu, üzgün, kızgın duygu durumlarının çeşitli şekillerle sunumunu içermektedir. Katılımcılar o anda kendilerini nasıl hissettikleri ile ilgili yüz ifadesini bulup işaretlemektedirler.

\section{Verilerin Analizi}

Elde edilen verilerin analizinde; öğretmen adaylarına ilişkin demografik özelliklerin değerlendirilmesinde frekans ve yüzde gibi betimsel istatistikler kullanılmıştır.

Öğretmen adaylarının Voltan Acar Kendini Belirleme (Güvengenlik) Ölçeği'nden aldıkları puanların normal dağılıp dağılmadığını belirlemek amacıyla Kolmogorov-Smirnov (K-S) normallik testi yapılmıştır. Kolmogorov-Smirnov (K-S) normallik testi sonucunda normal dağılım gösteren gruplarda, gruplar arası farklılık incelenirken ikili gruplar için bağımsız örneklemler t testi, ikiden fazla gruplar için ise Tek Faktörlü Anova kullanılmıştır. Kolmogorov-Smirnov (K-S) normallik testi sonucunda normal dağılım göstermeyen gruplarda ise, gruplar arası farklılık incelenirken ikili gruplar için Mann Whitney U Testi, ikiden fazla gruplarda ise Kruskal Wallis H Testi kullanılmıştır. Gruplar arası farklılık incelenirken; anlamlılık düzeyi olarak .05 kullanılmış olup $p<.05$ olması durumunda gruplar arası anlamlı farklılığın olduğu, $\mathrm{p}>.05$ olması durumunda ise gruplar arası anlamlı farklılı̆̆ın olmadı̆̆ belirtilmiştir (Büyüköztürk, Kılıç, Akgün, Kardeniz, \& Demirel, 2011). 


\section{Bulgular}

Öğretmen adaylarının güvengenlik düzeylerinin; duygu durumları (o anda kendilerini nasıl hissettikleri), cinsiyet, yaş, bölüm, aile tipi, doğum sırası, arkadaşları ile algıladıkları iletişim düzeylerine göre, farklılık gösterip göstermediğini incelemek amacıyla yapılan bu araştırmadan elde edilen bulgular aşağıda tablolar halinde sunulmuştur.

Tablo 1

Öğretmen Adaylarının Cinsiyetlerine Göre Voltan Acar Kendini Belirleme Envanteri Puanlarına Illişkin Mann Whitney U Testi ve t Testi Sonuçları

\begin{tabular}{|c|c|c|c|c|c|c|c|}
\hline \multirow{2}{*}{ VAKBE } & \multirow{2}{*}{ Cinsiyet } & \multirow{2}{*}{$n$} & \multirow{2}{*}{$\overline{\boldsymbol{X}}$} & \multirow{2}{*}{$\widehat{\boldsymbol{X}}$} & \multirow{2}{*}{ ss } & \multicolumn{2}{|c|}{ t test } \\
\hline & & & & & & $t$ & $p$ \\
\hline \multirow{4}{*}{ Çekingen } & Erkek & 92 & 69.88 & 68.5 & 13.69 & \multirow{2}{*}{0.487} & \multirow{2}{*}{.626} \\
\hline & Kadın & 373 & 69.10 & 69.00 & 13.85 & & \\
\hline & & & & & & \multicolumn{2}{|c|}{$\begin{array}{c}\text { MannWhitney } U \\
\text { Testi }\end{array}$} \\
\hline & & & & & & $U$ & $p$ \\
\hline \multirow{2}{*}{ Güvengen } & Erkek & 92 & 48.52 & 50.50 & 9.14 & \multirow{2}{*}{16.423} & \multirow{2}{*}{.524} \\
\hline & Kadın & 373 & 48.36 & 48.00 & 8.47 & & \\
\hline \multirow{2}{*}{ Toplam } & Erkek & 92 & 118.40 & 119.00 & 19.33 & \multirow{2}{*}{16.700} & \multirow{2}{*}{.692} \\
\hline & Kadın & 373 & 117.45 & 117.00 & 19.30 & & \\
\hline
\end{tabular}

$* p>.05$

Tablo 1 incelendiğinde, öğretmen adaylarının cinsiyetlerine göre Voltan Acar Kendini Belirleme Ölçeği'nin Çekingen Alt Boyutu, Güvengen Alt Boyutu ve toplam puanları arasında istatistiksel olarak anlamlı derecede farklılık olmadığı görülmektedir (p>.05). Bu sonuca göre, öğretmen adaylarının güvengenlik düzeylerinde cinsiyet değişkeninin etkili olmadığ söylenebilir.

Tablo 2 incelendiğinde, öğretmen adaylarının yaşlarına göre Voltan Acar Kendini Belirleme Ölçeği'nin Çekingen Alt Boyutu $\left(\mathrm{X}^{2}=9.814, p<.05\right)$ ve toplam puanları arasındaki $\left(\mathrm{X}^{2}=9.039, p<.05\right)$ fark istatistiksel olarak anlamlı bulunurken, Güvengen Alt Boyutu $\left(\mathrm{X}^{2}=6.726, \mathrm{p}>.05\right)$ puanları arasında ise fark istatistiksel olarak anlamlı bulunmamıştır. Çekingen alt boyutu puanının, 22 yaşında olanların 22 yaşından küçük olanlardan anlamlı derecede yüksek olduğu görülmektedir. Güvengenlik alt boyutu puanının, 22 ve üzeri yaşta olanların 20 yaşında olanlardan anlamlı derecede yüksek olduğu görülmektedir. Bu sonuca göre, öğretmen adaylarının güvengenlik düzeylerinde öğretmen adaylarının yaşları değişkeninin etkili olduğu söylenebilir. 
Tablo 2

Ögretmen Adaylarının Yaşlarına Göre Voltan Acar Kendini Belirleme Envanteri Puanlarına Illişkin Kruskall-Wallis H Testi Sonuçları

\begin{tabular}{|c|c|c|c|c|c|c|c|c|}
\hline \multirow[t]{2}{*}{$V A K B E$} & \multirow[t]{2}{*}{ Yaş } & \multirow[t]{2}{*}{$\mathrm{n}$} & \multirow[t]{2}{*}{$\bar{X}$} & \multirow{2}{*}{$\widehat{\boldsymbol{X}}$} & \multirow[t]{2}{*}{ ss } & \multicolumn{2}{|c|}{$\begin{array}{c}\text { Kruskal Wallis } \\
\text { H Testi }\end{array}$} & \multirow{2}{*}{$\begin{array}{l}\text { Anlamlı } \\
\text { Farklılık }\end{array}$} \\
\hline & & & & & & $X^{2}$ & $p$ & \\
\hline \multirow{4}{*}{ Çekingen } & $\leq 20$ & 105 & 67.46 & 68.00 & 12.15 & \multirow{4}{*}{9.814} & \multirow{4}{*}{$.020 *$} & \\
\hline & 21 & 180 & 67.79 & 66.00 & 14.64 & & & $20-22$ \\
\hline & 22 & 123 & 71.72 & 73.00 & 13.79 & & & $21-22$ \\
\hline & $\geq 23$ & 57 & 71.86 & 72.00 & 13.18 & & & \\
\hline \multirow{4}{*}{$\begin{array}{c}\text { Güvengen Alt } \\
\text { Boyut }\end{array}$} & $\leq 20$ & 105 & 47.06 & 47.00 & 7.8 & \multirow{4}{*}{6.726} & \multirow{4}{*}{.081} & \\
\hline & 21 & 180 & 48.31 & 48.00 & 8.14 & & & \\
\hline & 22 & 123 & 48.89 & 49.00 & 9.64 & & & \\
\hline & $\geq 23$ & 57 & 50.04 & 52.00 & 8.84 & & & \\
\hline \multirow{4}{*}{ Toplam } & $\leq 20$ & 105 & 114.51 & 115.00 & 17.14 & \multirow{4}{*}{9.039} & \multirow{4}{*}{$.029 *$} & \multirow{4}{*}{$\begin{array}{l}20-22 \\
20-23\end{array}$} \\
\hline & 21 & 180 & 116.09 & 113.00 & 19.91 & & & \\
\hline & 22 & 123 & 120.60 & 120.00 & 20.05 & & & \\
\hline & $\geq 23$ & 57 & 121.89 & 121.00 & 18.23 & & & \\
\hline
\end{tabular}

$* p>.05$

Tablo 3 incelendiğinde, öğretmen adaylarının öğretmenlik alanlarına göre Voltan Acar Kendini Belirleme Ölçeği'nin Güvengen Alt Boyutu (X2=21.384, $p<.05$ ) ve toplam puanları arasındaki $(\mathrm{X} 2=18.15, p<.05)$ fark istatistiksel olarak anlaml bulunurken, Çekingen Alt Boyutu (X2=10.76, $\mathrm{p}>.05)$ puanları arasındaki fark ise istatistiksel olarak anlamlı bulunmamıştır. Güvengen alt boyutu puanlarının, Sosyal Bilgiler Eğitimi öğretmen adaylarının Matematik eğitimi öğretmen adaylarına göre, Türkçe Eğitimi öğretmen adaylarının Matematik eğitimi öğretmen adaylarına göre, Fen Eğitimi öğretmen adaylarının Matematik eğitimi öğretmen adaylarına göre, Sınıf Eğitimi öğretmen adaylarının Matematik eğitimi öğretmen adaylarına göre, Okul Öncesi Eğitimi öğretmen adaylarının Matematik eğitimi öğretmen adaylarına göre anlamlı derecede yüksek olduğu görülmektedir. Voltan Acar Kendini Belirleme Ölçeği toplam puanlarının, Sosyal Bilgiler Eğitimi öğretmen adaylarının Türkçe ve Matematik Eğitimi öğretmen adaylarına göre, Türkçe Eğitimi öğretmen adaylarının Okul Öncesi Eğitimi öğretmen adaylarına göre, Fen Eğitimi öğretmen adaylarının Matematik Eğitimi öğretmen adaylarına göre, Sınıf Eğitimi öğretmen adaylarının Matematik Eğitimi öğretmen adaylarına göre, Okul Öncesi Eğitimi öğretmen adaylarının Matematik Eğitimi öğretmen adaylarına göre anlamlı derecede yüksek olduğu görülmektedir. Bu sonuca göre, öğretmen adaylarının güvengenlik düzeylerinde öğretmenlik alanları değişkeninin etkili olduğu söylenebilir. 


\section{Tablo 3}

Öğretmen Adaylarının Öğretmenlik Alanlarına Göre Voltan Acar Kendini Belirleme Envanteri Puanlarına İlişkin Kruskall-Wallis H Testi Sonuçları

\begin{tabular}{|c|c|c|c|c|c|c|c|c|}
\hline \multirow[t]{2}{*}{$V A K B E$} & \multirow{2}{*}{$\begin{array}{c}\text { Öğretmenlik } \\
\text { Alanları }\end{array}$} & \multirow[t]{2}{*}{$\mathrm{n}$} & \multirow[t]{2}{*}{$\overline{\boldsymbol{X}}$} & \multirow[t]{2}{*}{$\widehat{\boldsymbol{X}}$} & \multirow[t]{2}{*}{ ss } & \multicolumn{2}{|c|}{$\begin{array}{c}\text { Kruskal Wallis } \\
\text { H Testi }\end{array}$} & \multirow{2}{*}{$\begin{array}{l}\text { Anlamlı } \\
\text { Farklılık }\end{array}$} \\
\hline & & & & & & $X^{2}$ & $p$ & \\
\hline \multirow[t]{6}{*}{ Çekingen } & $\begin{array}{l}\text { Sosyal Bilgiler } \\
\text { Eğitimi }\end{array}$ & 59 & 72.08 & 69 & 13.71 & \multirow{6}{*}{10.76} & \multirow{6}{*}{.056} & \\
\hline & Türkçe Eğitimi & 72 & 66.47 & 66,5 & 13.8 & & & \\
\hline & $\begin{array}{l}\text { Matematik } \\
\text { Eğitimi }\end{array}$ & 78 & 66.11 & 67 & 13.19 & & & \\
\hline & $\begin{array}{l}\text { Fen Bilgisi } \\
\text { Eğitimi }\end{array}$ & 67 & 70.20 & 71 & 14.16 & & & \\
\hline & Sınıf Eğitimi & 63 & 70.03 & 70 & 13.86 & & & \\
\hline & $\begin{array}{l}\text { Okul Öncesi } \\
\text { Eğitimi }\end{array}$ & 126 & 70.55 & 71,5 & 13.67 & & & \\
\hline \multirow[t]{6}{*}{ Güvengen } & $\begin{array}{l}\text { Sosyal Bilgiler } \\
\text { Eğitimi }\end{array}$ & 59 & 49.79 & 52 & 9.053 & \multirow{6}{*}{21.38} & \multirow{6}{*}{.001} & $\begin{array}{c}\text { Sosyal- } \\
\text { Matematik }\end{array}$ \\
\hline & Türkçe Eğitimi & 72 & 47.94 & 49 & 7.92 & & & Türkçe- \\
\hline & $\begin{array}{l}\text { Matematik } \\
\text { Eğitimi }\end{array}$ & 78 & 44.85 & 44 & 7.94 & & & $\begin{array}{c}\text { Matematik } \\
\text { Fen- }\end{array}$ \\
\hline & $\begin{array}{l}\text { Fen Bilgisi } \\
\text { Eğitimi }\end{array}$ & 67 & 49.11 & 48 & 7.96 & & & $\begin{array}{l}\text { Matematik } \\
\text { Sinıf- } \\
\text { Matematik }\end{array}$ \\
\hline & Sınıf Eğitimi & 63 & 48.33 & 50 & 9.32 & & & Okul \\
\hline & $\begin{array}{l}\text { Okul Öncesi } \\
\text { Eğitimi }\end{array}$ & 126 & 49.80 & 50,5 & 8.60 & & & $\begin{array}{c}\text { Oncesi- } \\
\text { Matematik }\end{array}$ \\
\hline \multirow{6}{*}{ Toplam } & $\begin{array}{l}\text { Sosyal Bilgiler } \\
\text { Eğitimi }\end{array}$ & 59 & 121.88 & 120 & 20.66 & \multirow{6}{*}{18.15} & \multirow{6}{*}{.003} & $\begin{array}{l}\text { Sosyal- } \\
\text { Türkçe }\end{array}$ \\
\hline & Türkçe Eğitimi & 72 & 114.41 & 113.5 & 17.60 & & & $\begin{array}{c}\text { Sosyal- } \\
\text { Matematik }\end{array}$ \\
\hline & $\begin{array}{l}\text { Matematik } \\
\text { Eğitimi }\end{array}$ & 78 & 110.97 & 110 & 18.67 & & & $\begin{array}{c}\text { Okul } \\
\text { Öncesi- }\end{array}$ \\
\hline & $\begin{array}{l}\text { Fen Bilgisi } \\
\text { Eğitimi }\end{array}$ & 67 & 119.32 & 120 & 18.21 & & & $\begin{array}{l}\text { Türkçe } \\
\text { Fen- }\end{array}$ \\
\hline & Sınıf Eğitimi & 63 & 118.36 & 119 & 18.98 & & & $\begin{array}{l}\text { Matematik } \\
\text { Sinıf- }\end{array}$ \\
\hline & $\begin{array}{l}\text { Okul Öncesi } \\
\text { Eğitimi }\end{array}$ & 126 & 120.36 & 120,5 & 19.67 & & & $\begin{array}{c}\text { Matematik } \\
\text { Okul } \\
\text { Öncesi- } \\
\text { Matematik }\end{array}$ \\
\hline
\end{tabular}


Tablo 4 incelendiğinde; öğretmen adaylarının aile tiplerine göre Voltan Acar Kendini Belirleme Ölçeği’nin Çekingen Alt Boyutu $\left(\mathrm{X}^{2}=7.956, p<.05\right)$ ve toplam puanları arasındaki $\left(\mathrm{X}^{2}=7.307, p<.05\right)$ fark istatistiksel olarak anlamlı iken, Güvengen Alt Boyutu $\left(\mathrm{X}^{2}=3.183, \mathrm{p}>.05\right)$ puanları arasında ise fark istatistiksel olarak anlaml bulunmamıştır. Çekingen alt boyutu puanlarının, çekirdek ailesi olan öğretmen adaylarının geniş ailesi olan öğretmen adaylarına göre anlamlı derecede yüksek olduğu görülmüştür. $\mathrm{Bu}$ sonuca göre, öğretmen adaylarının güvengenlik düzeylerinde aile tipi değişkenin etkili olduğu söylenebilir.

Tablo 4

Ö̆gretmen Adaylarının Aile Tiplerine Göre Voltan Acar Kendini Belirleme Envanteri Puanlarına İlişkin Kruskall-Wallis H Testi Sonuçları

\begin{tabular}{|c|c|c|c|c|c|c|c|c|}
\hline \multirow[t]{2}{*}{$V A K B E$} & \multirow[t]{2}{*}{ Yaş } & \multirow[t]{2}{*}{$\mathrm{n}$} & \multirow[t]{2}{*}{$\bar{X}$} & \multirow[t]{2}{*}{$\widehat{\boldsymbol{X}}$} & \multirow[t]{2}{*}{ Ss } & \multicolumn{2}{|c|}{$\begin{array}{c}\text { Kruskal Wallis } \\
\text { H Testi }\end{array}$} & \multirow{2}{*}{$\begin{array}{l}\text { Anlaml1 } \\
\text { Farkl111k }\end{array}$} \\
\hline & & & & & & $X^{2}$ & $p$ & \\
\hline \multirow[t]{3}{*}{ Çekingen } & Geniş & 74 & 65.75 & 66 & 14.02 & & & \\
\hline & Çekirdek & 381 & 70.13 & 70 & 13.56 & 7.956 & .019 & $\begin{array}{l}\text { Çekirdek- } \\
\text { Geniş }\end{array}$ \\
\hline & Tek ebeveynli & 10 & 61.30 & 62 & 16.39 & & & \\
\hline \multirow[t]{3}{*}{ Güvengen } & Geniş & 74 & 47.41 & 47 & 8.26 & & & \\
\hline & Çekirdek & 381 & 48.69 & 49 & 8.57 & 3.813 & .149 & \\
\hline & Tek ebeveynli & 10 & 44.0 & 43 & 10.89 & & & \\
\hline \multirow[t]{3}{*}{ Toplam } & Geniş & 74 & 113.17 & 113 & 18.66 & & & \\
\hline & Çekirdek & 381 & 118.83 & 119 & 19.04 & 7.307 & .026 & $\begin{array}{l}\text { Çekirdek- } \\
\text { Geniş }\end{array}$ \\
\hline & Tek ebeveynli & 10 & 105.30 & 101 & 25.56 & & & \\
\hline
\end{tabular}

Tablo 5 incelendiğinde, öğretmen adaylarının doğum sıralarına göre, Voltan Acar Kendini Belirleme Ölçeği'nin Çekingen Alt Boyutu, Güvengen Alt Boyutu ve toplam puanları arasında istatistiksel olarak anlamlı derecede bir fark çıkmamıştır ( $p>.05)$. Bu sonuca göre, öğretmen adaylarının güvengenlik düzeylerinde doğum sırası değişkeninin etkili olmadığı söylenebilir. 
Tablo 5

Öğretmen Adaylarının Doğum Stralarına Göre Voltan Acar Kendini Belirleme Envanteri Puanlarına İlişkin Kruskall-Wallis H Testi Sonuçları

\begin{tabular}{|c|c|c|c|c|c|c|c|}
\hline \multirow{2}{*}{$V A K B E$} & \multirow{2}{*}{ Yaş } & \multirow{2}{*}{$\mathrm{n}$} & \multirow{2}{*}{$\overline{\boldsymbol{X}}$} & \multirow{2}{*}{$\widehat{\boldsymbol{X}}$} & \multirow{2}{*}{ ss } & \multicolumn{2}{|c|}{ Kruskal Wallis H Test } \\
\hline & & & & & & $X^{2}$ & $p$ \\
\hline \multirow[t]{4}{*}{ Çekingen } & İlk & 203 & 68.73 & 67 & 13.47 & & \\
\hline & Orta & 119 & 68.90 & 69 & 12.97 & 1.713 & . 425 \\
\hline & Son & 143 & 70.16 & 70 & 14.96 & & \\
\hline & İlk & 203 & 48.78 & 49 & 8.54 & & \\
\hline \multirow[t]{3}{*}{ Güvengen } & Orta & 119 & 47.81 & 48 & 8.72 & 1.894 & .388 \\
\hline & Son & 143 & 48.86 & 49 & 8.57 & & \\
\hline & İlk & 203 & 117.52 & 116 & 19.00 & & \\
\hline \multirow[t]{2}{*}{ Toplam } & Orta & 119 & 116.72 & 116 & 18.43 & 1.681 & .431 \\
\hline & Son & 143 & 119.03 & 120 & 20.41 & & \\
\hline
\end{tabular}

$* p>.05$

Tablo 6

Öğretmen Adaylarının Algıladıkları İletişim Becerilerine Göre Voltan Acar Kendini Belirleme Envanteri Puanlarına İlişkin Kruskal-Wallis H Testi Sonuçları

\begin{tabular}{|c|c|c|c|c|c|c|c|c|}
\hline \multirow{2}{*}{$V A K B E$} & \multirow{2}{*}{$\begin{array}{l}\text { İletişim } \\
\text { Becerileri }\end{array}$} & \multirow{2}{*}{$\mathrm{n}$} & \multirow{2}{*}{$\bar{X}$} & \multirow{2}{*}{$\widehat{\boldsymbol{X}}$} & \multirow{2}{*}{ ss } & \multicolumn{2}{|c|}{$\begin{array}{c}\text { Kruskal Wallis } \\
\text { H Testi }\end{array}$} & \multirow{2}{*}{$\begin{array}{l}\text { Anlaml1 } \\
\text { Farklılık }\end{array}$} \\
\hline & & & & & & $X^{2}$ & $p$ & \\
\hline \multirow[t]{4}{*}{ Çekingen } & İyi & 361 & 70.98 & 71 & 13.46 & & & \\
\hline & Orta & 98 & 62.90 & 64 & 13.37 & 28.124 & .000 & İyi-Orta \\
\hline & Kötü & 6 & 68.33 & 65.5 & 12.95 & & & \\
\hline & İyi & 361 & 49.56 & 50 & 8.47 & & & \\
\hline \multirow[t]{3}{*}{ Güvengen } & Orta & 98 & 44.35 & 45 & 7.8 & 32.861 & .000 & İyi-Orta \\
\hline & Kötü & 6 & 43.33 & 45 & 7.6 & & & \\
\hline & İyi & 361 & 120.55 & 120 & 18.54 & & & \\
\hline \multirow[t]{2}{*}{ Toplam } & Orta & 98 & 107.26 & 106 & 18.73 & 39.344 & .000 & İyi-Orta \\
\hline & Kötü & 6 & 111.66 & 109.5 & 14.37 & & & \\
\hline
\end{tabular}

Tablo 6 incelendiğinde; öğretmen adaylarının algıladıkları iletişim becerilerine göre Voltan Acar Kendini Belirleme Ölçeği'nin Çekingen Alt Boyutu $\left(X^{2}=28.124\right.$, $p<.05)$, Güvengen Alt Boyutu $\left(\mathrm{X}^{2}=32.361, p<.05\right)$ ve toplam puanları arasinda $\left(\mathrm{X}^{2}=39.344, p<.05\right)$ fark istatistiksel olarak anlamlı bulunmuştur. Çekingen Alt Boyutu, 
Güvengen Alt Boyutu ve toplam puanının, iletişim becerileri iyi düzeyde olan öğretmen adaylarında, iletişim becerileri orta düzeyde olan öğretmen adaylarına göre anlamlı derecede yüksek çıkmıştır. $\mathrm{Bu}$ sonuca göre, öğretmen adaylarının güvengenlik düzeylerinde algıladıkları iletişim becerileri değişkeninin etkili olduğu söylenebilir.

Tablo 7 incelendiğinde, öğretmen adaylarının duygu durumlarına göre Voltan Acar Kendini Belirleme Ölçeği'nin Çekingen Alt Boyutu ( $\mathrm{F}=6.828, p<.01)$, Güvengen Alt Boyutu $\left(\mathrm{X}^{2}=14.011, p<.05\right)$ ve toplam puanları arasında $\left(\mathrm{X}^{2}=24.445, p<.05\right)$ fark istatistiksel olarak anlamlı bulunmuştur. Çekingen alt boyutu puanının, mutlu olanların kafası karışık, ciddi ve üzgün olanlardan anlamlı derecede yüksek çıkmıştır. Güvengen alt boyutu puanının, mutlu olanların kafası karışık, ciddi ve üzgün olanlardan anlamlı derecede yüksek olduğu görülmektedir. Toplam puanlara bakıldığında ise, mutlu olanların kafası karışık, ciddi ve üzgün olanlardan; kızgın olanların kafası karışık, ciddi ve üzgün olanlardan anlamlı derecede yüksek olduğu görülmektedir.

\section{Tablo 7}

Öğretmen Adaylarının Duygu Durumlarına Göre Voltan Acar Kendini Belirleme Envanteri Puanlarına Illişkin Anova ve Kruskal-Wallis H Testi Sonuçları

\begin{tabular}{|c|c|c|c|c|c|c|c|c|}
\hline \multirow{2}{*}{$V A K B E$} & \multirow{2}{*}{$\begin{array}{c}\text { Duygu } \\
\text { Durumları }\end{array}$} & \multirow{2}{*}{$\mathrm{n}$} & \multirow{2}{*}{$\overline{\boldsymbol{X}}$} & \multirow{2}{*}{$\widehat{\boldsymbol{X}}$} & \multirow{2}{*}{ ss } & \multicolumn{2}{|c|}{ ANOVA } & \multirow{2}{*}{$\begin{array}{l}\text { Anlamlı } \\
\text { Farklıl1k }\end{array}$} \\
\hline & & & & & & $F$ & $p$ & \\
\hline \multirow[t]{5}{*}{ Çekingen } & Kafası karışık & 50 & 68.30 & 68 & 14.05 & \multirow{5}{*}{6.828} & \multirow{5}{*}{$.000 *$} & \multirow{5}{*}{$\begin{array}{l}\text { Mutlu-Ciddi } \\
\text { Mutlu-Üzgün }\end{array}$} \\
\hline & Ciddi & 69 & 64.26 & 66 & 13.11 & & & \\
\hline & Mutlu & 220 & 72.01 & 71 & 12.94 & & & \\
\hline & Üzgün & 84 & 65.40 & 64.5 & 14.88 & & & \\
\hline & $\begin{array}{l}\text { Kizgın veya } \\
\text { kindar }\end{array}$ & 42 & 71.81 & 72.5 & 13.19 & & & \\
\hline
\end{tabular}

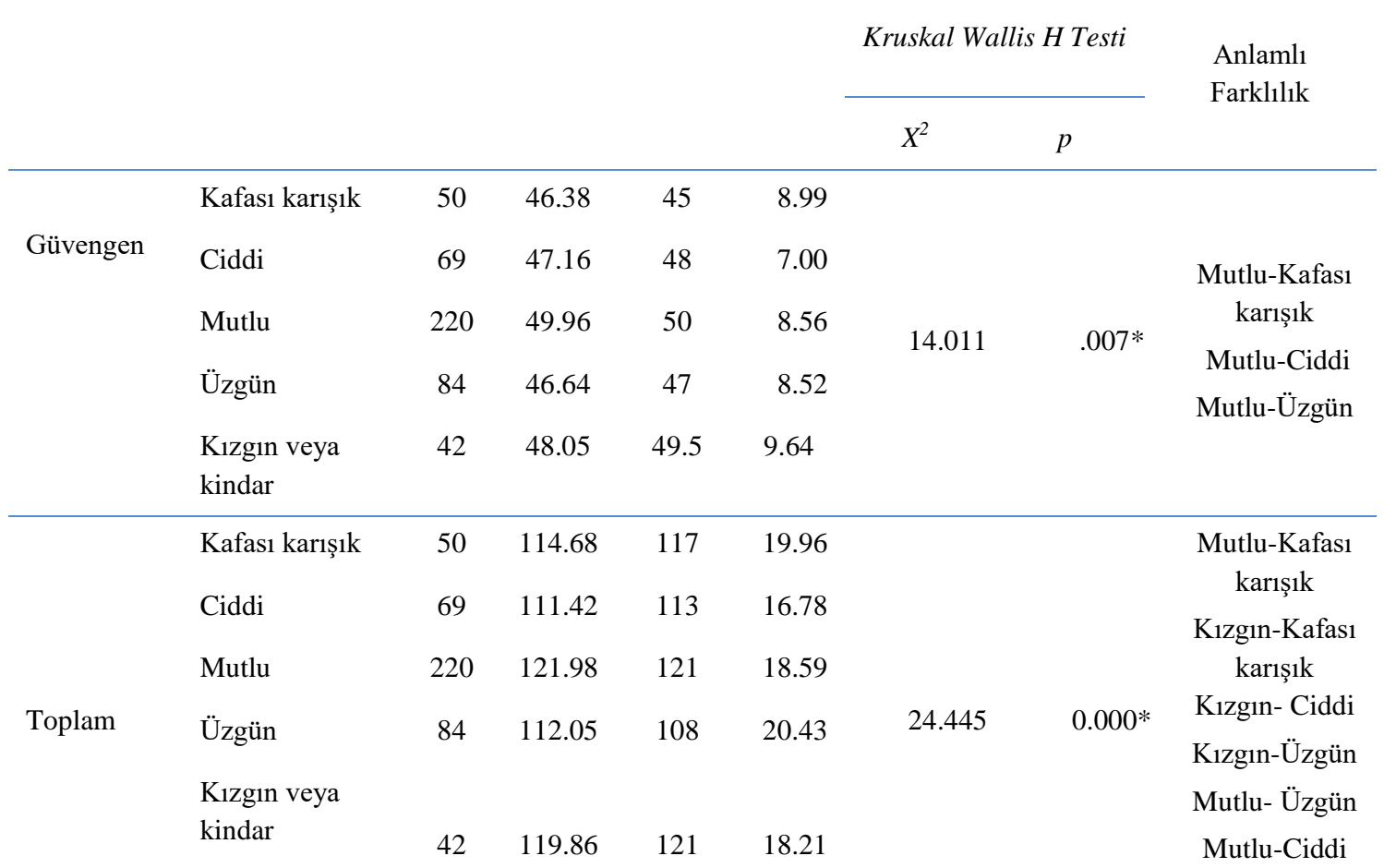




\section{Sonuç ve Tartışma}

Öğretmen adaylarının lisans eğitimleri sırasında, kendi kararlarını alabilmeleri, sorumluluklarını yerine getirebilmeleri, problemlere etkili çözüm yolları bulabilmeleri beklenir. Bütün bunlardan yola çıkılarak öğretmen adaylarının güvengen davranışlara sahip olmaları gerektiği söylenebilir (Ateş, 2016). Ayrıca öğretmen adaylarının güvengenlik düzeylerinin yüksek olması, ileriki meslek yaşantılarında kişilerarası olumlu ilişkiler kurmalarına da katkı sağlayabilir.

Öğretmen adaylarının güvengenlik düzeylerinin o anki duygu durumları ve bazı demografik özellikler (cinsiyet, yaş, öğretmenlik alanı, aile tipi, doğum sırası, iletişim becerileri) açısından incelenmesi amacıyla gerçekleştirilen bu çalışma sonucunda, öğretmen adaylarının cinsiyetlerine göre Voltan Acar Kendini Belirleme Ölçeği'nin Çekingen Alt Boyutu, Güvengen Alt Boyutu ve toplam puanları arasında istatistiksel olarak anlamlı derecede farklılık olmadığı belirlenmiştir. Güven (2010) meslek yüksekokullarına devam eden öğrencilerin güvengenlik ve problem çözme becerilerini farklı değişkenler açısından incelediği çalışma sonucunda, öğrencilerin güvengenlik düzeyleri ve problem çözme becerileri ile cinsiyet değişkeni arasında anlamlı bir farklılık bulunmamıştır. Aynı şekilde Rezayat ve Dehghan Nayeri (2014) hemşirelik bölümündeki öğrencilerin depresyon ve güvengenlik düzeyleri arasındaki ilişkiyi inceledikleri çalışmada, cinsiyet değişkeninin güvengenlik düzeylerinde etkili olmadığ sonucuna ulaşmışlardır. Adana, Aktaş, Erdağı, Eliş, Alkan ve Uluman (2009) hemşirelik ve sağlık memurluğu bölümündeki öğrencilerin atılganlık düzeylerini inceledikleri çalışmanın sonucunda cinsiyetin atılganlık düzeyini etkilemediği sonucuna ulaşmışlardır. Uzuntarla, Uğrak ve Cihangiroğlu (2016) üniversite öğrencilerinin sürekli kaygı ile atılganlık arasındaki ilişkinin incelenmesi amacıyla gerçekleştirdikleri çalışmada da cinsiyete göre sürekli kaygı ve atılganlık düzeylerinde istatistiksel olarak anlamlı farklılık bulunmamıştır. Twenge (2001) kadınların değişen rollerinin atılganlığa olan etkisini incelediği metaanaliz çalışmasında kadınlar ve erkeklerin atılganlık düzeyleri arasında farklılık olmadığını belirtmişlerdir. Cinsiyet değişkeninin güvengenlik düzeyinde etkili olmadığı sonucu, alanyazında yapılan diğer çalışmaların sonuçları ile benzerlik göstermektedir. Geçmişten günümüze toplumsal yapıda meydana gelen değişimler, her iki cinsiyetin de güvengen davranışlara sahip olmalarını gerektirdiği için böyle bir sonucun ortaya çıktığı söylenebilir.

Öğretmen adaylarının yaşlarına göre Voltan Acar Kendini Belirleme Ölçeği’nin Çekingen Alt Boyutu ve toplam puanları arasındaki fark istatistiksel olarak anlamlı bulunurken, Güvengen Alt Boyutu puanları arasında ise fark istatistiksel olarak anlamlı bulunmamıştır. Araştırmada çekingen alt boyutu puanının, 22 yaşında olanların 22 yaşından küçük olanlardan, güvengenlik alt boyutu puanının, 22 ve üzeri yaşta olanların 20 yaşında olanlardan anlamlı derecede yüksek olduğu belirlenmiş̧tir. Yaşla birlikte artan güvengenlik düzeyi, kişiler arası ilişkilerdeki deneyimlerin artması şeklinde açıklanabilir (Dinçyürek, Çağlar \& Birol, 2010). Parlar Kılıç ve Sevinç (2018) hemşirelik bölümünde okuyan öğrencilerin güvengenlik düzeyleri ile kültürel hassasiyetleri arasındaki ilişkiyi inceledikleri çalışmada, yaş ile güvengenlik düzeyi arasında anlamlı farklılığın olduğu sonucuna ulaşmışlardır. Alanyazında bu araştırma sonucunda olduğu gibi yaş ilerledikçe, güvengenlik düzeyinin de arttığı sonucuna ulaşan başka çalışmalar da bulunmaktadır (Arslantaş, Adana \& Şahbaz, 2013; Küçükkaragöz ve diğerleri, 2013). Bireylerin yaşları ilerledikçe edindikleri bilgi ve 
deneyimler artış gösterir. Buna bağlı olarak da bireylerin kendilerine olan güvenleri artar, güvengenlik düzeylerinde artış olur. $\mathrm{Bu}$ çalışmada elde edilen yaş arttıkça güvengenlik düzeyinin artmasının bununla ilişkisi olduğu düşünülebilir.

Öğretmen adaylarının öğretmenlik alanlarına göre Voltan Acar Kendini Belirleme Ölçeği'nin Güvengen Alt Boyutu ve toplam puanları arasındaki fark istatistiksel olarak anlamlı bulunurken, Çekingen Alt Boyutu puanları arasındaki fark ise istatistiksel olarak anlamlı bulunmamıştır. Benzer şekilde Akeren (2017) üniversite öğrencilerinde algılanan sosyal destek ve güvengenliğin psikolojik yardım gereksinimini yordama düzeyini incelediği araştırmada, psikolojik yardım gereksiniminin öğrenim görülen fakülteye göre farklılaştığı ve eğitim fakültesi öğrencilerinin güvenlik gereksinimlerinin mühendislik fakültesi öğrencilerine göre daha yüksek olduğunu belirlemiştir. Bölümler arası farklılıklara bakıldığında, özellikle Okul Öncesi, Sınıf, Sosyal Bilgiler, Türkçe Eğitimi gibi derslerin sözel ağırlıklı ve psikoloji, iletişim gibi alanlarda derslerin yer aldığı programlarda öğrenim görmekte olan öğrencilerin, daha sayısal ağırlıklı derslerin yer aldığı Matematik ve Fen eğitiminde öğrenim görmekte olan adaylara göre güvengenlik düzeylerinin yüksek olduğu ortaya çıkmıştır.

Öğretmen adaylarının doğum sırasına göre, Voltan Acar Kendini Belirleme Ölçeği'nin Çekingen Alt Boyutu, Güvengen Alt Boyutu ve toplam puanları arasında istatistiksel olarak anlamlı derecede farklılık olmadığı belirlenmiştir. Araştırma sonucuna benzer şekilde Yogaranee (2016) de eğitim fakültesindeki kız öğrencilerin güvengenlik düzeylerini belirlemek amacıyla gerçekleştirdiği araştırmada, doğum sırasının güvengenlik düzeylerinde etkili olmadığ 1 sonucunu elde etmiştir. Uğurluoğlu (1996) da lise öğrencileri ile yaptığı çalışmanın sonucunda doğum sırasının güvengenlik düzeyinde etkili olmadığı sonucuna ulaşmıştır. Güvengenlik, yıllar geçtikçe artan bigi ve deneyime doğrultusunda gelişir. Güvengenlik düzeyinin küçük yaşlarda, doğum sırası gibi nedenlerden etkilense de ileriki yaşlarda güvengenlik düzeyinin edinilen bilgi ve deneyim doğrultusunda pozitif yönde gelişmesi beklenir. Bu çalışmada da bu sebeple anlamlı farklılık olmadığı söylenebilir.

Öğretmen adaylarının algıladıkları iletişim becerilerine göre Voltan Acar Kendini Belirleme Ölçeği'nin Çekingen Alt Boyutu, Güvengen Alt Boyutu ve toplam puanları arasındaki fark istatistiksel olarak anlamlı bulunmuştur. Güvengenlik becerileri, kişisel becerilerin ve etkileşimlerin niteliğinin geliştirilmesi için gereklidir (Hamoud, Abd El Dayem \& Ossman, 2011). Benzer Haladin, Ibrahim ve Rajab (2013), Malezyadaki üniversite öğrencilerinin güvengenlik becerilerini inceledikleri çalışmada, öğrencilerin güvengenlik düzeyleri ile iletişim becerileri arasında pozitif yönde doğrusal bir ilişki olduğu sonucuna ulaşmışlardır. Öğretmenlerin iletişim ve güvengenlik becerilerinin yüksek olması, öğrencilerinin sosyal becerilerinin gelişiminde büyük bir etki yaratabilir. Martínez, Justicia ve Haro (2016) sınıf öğretmenlerinin güvengenlik düzeylerinin, çocukların sosyal becerileri üzerindeki etkisini incelediği çalışmada, öğretmenlerin sahip oldukları güvengen davranışların, çocukların sosyal becerilerinin gelişiminde etkili olduğu sonucuna ulaşmışlardır. Buradan yola çıkılarak güvengenlik becerilerinin doğrudan iletişim becerileri ile bağlantılı olduğu söylenebilir. Bu nedenle eğitim ortamlarında çocukların güvengenlik ve iletişim becerilerinin geliştirilmesine yönelik düzenlemeler yapılması önemlidir. Yamada, Maeuezato ve Ohtsu (2013) ilkokul 5. sınıftaki çocuklara verilen yaşam becerileri eğitiminin çocukların güvengenlik 
ve iletişim becerileri üzerindeki etkisini inceledikleri çalışmada, verilen eğitim sonrasında çocukların iletişim becerilerinin ve güvengenlik düzeylerinin arttığını belirlemişlerdir.

Öğretmen adaylarının o anki duygu durumlarına göre Voltan Acar Kendini Belirleme Ölçeği'nin Çekingen Alt Boyutu, Güvengen Alt Boyutu ve toplam puanları arasında istatistiksel olarak anlamlı fark bulunmuştur $(p<.05)$. Maqbool Parray \& Kumar (2017) güvengenlik eğitiminin, ergenlerin benlik algısı, güvengenlik, duygusal iyi oluşluk, stres düzeyleri üzerindeki etkilerini araştırdıkları çalışmada, verilen eğitim sonrasında ergenlerin stres düzeylerinin büyük ölçüde düştüğü, benlik algısı, güvengenlik ve duygusal iyi oluşluk düzeylerinin arttığı sonuçlarını elde etmişlerdir. Benzer şekilde Ateş (2016) Rehberlik ve Psikolojik Danışmanlık bölümünde öğrenim görmekte olan öğretmen adaylarının güvengenlik düzeyleri ve sosyal destek algıları ile duygusal iyi oluşları arasındaki ilişkiyi incelediği çalışmada, öğretmen adaylarının duygusal iyi oluşlukları ile güvengenlik düzeyleri arasında pozitif yönde doğrusal bir ilişki belirlemiştir. $\mathrm{Bu}$ araştırmanın sonucunda olduğu gibi aanyazında yapılan diğer araştırmalarda da bireylerin duygusal iyi oluşlukları ve güvengenlik düzeyleri arasında pozitif yönde doğrusal bir ilişki olduğu ve güvengenlik eğitiminin stres düzeyini büyük ölçüde düşürdüğü vurgulamaktadır (Shafiq, Naz \& Yousaf, 2015; Eslami, Afzali, Hamidizadeh \& Masoudi, 2016).

\section{Öneriler}

$\mathrm{Bu}$ araştırmadan elde edilen bulgular doğrultusunda aşağıdaki öneriler sunulabilir:

- Öğretmen adaylarının lisans eğitimleri sırasında güvengenlik düzeylerini arttırmayı ve mesleki gelişimlerine katkı sunmayı planlayan güvengenlik eğitimleri hazırlanabilir.

- Öğretmenlerin mesleki yeterliliklerini ve iletişim becerilerini geliştirmeyi amaçlayan güvengenlik eğitimleri düzenlenebilir.

- Öğretmen adaylarının güvengenlik düzeyleri, duygusal iyi oluşlukları, benlik algıları, mesleğe yönelik tutumları arasındaki ilişkiyi bölümleri, almış oldukları dersler, katılmış oldukları kişisel gelişim seminerleri gibi farklı değişkenler açısından inceleyen daha kapsamlı çalışmalar gerçekleştirilebilir.

- Öğretmenlerin güvengenlik düzeyleri ile öğrencilerinin iletişim becerileri, duygusal iyi oluşluk, öğretmene ilişkin bakış açıları gibi farklı değişkenler arasındaki ilişkiyi inceleyen çalışmalar planlanabilir. 


\section{Summary}

Purpose and Significance: Characterized as young adults, university students are expected to possess high levels of assertiveness so that they can perform their occupational information and skills and so they can communicate effectively (Karagzoglu, Kahve, Koç \&Adamışoğlu, 2008). Especially for the professions that require effective communication skills, assertiveness training is to be of a significant place in an undergraduate education (Niusha, Farghadani \& Safari, 2012). Assertiveness is one of the prominent professional qualifications that should be a part of educational life, that reinforce interpersonal relationships and that teachers should possess (Mılovanovıç, Irkovı Mıladınovıç \& Stojanovi, 2016). In addition to being an important skill for an effective education, assertiveness contributes to improve interpersonal communication skills at school environments (Rusli, Nasir \& Hamzah, 2011). Teachers are expected to improve their assertiveness skills so as to establish an efficient and secure communication with their students (Unal, 2012). In this sense, this study aims to examine the teacher candidates' assertiveness levels in terms of their current moods and certain demographic features.

Method: This is a descriptive study designed in a scanning model which aims to examine whether teacher candidates' assertiveness levels differ in terms of their moods (how they feel at that moment), gender, age, department, family type, birth order and perceived communication level with their friends. The study population included $4654^{\text {th }}$ year classroom teacher candidates attending Afyon Kocatepe University, Education Faculty in the 2017-2018 academic years. Due to accessibility, the study population was accepted as the sample of the study. The data was collected during the fall term of the 2017-2018 academic years. Before the application, the participants were informed about the study, and their verbal consent was obtained. In this sense, among these 465 teacher candidates, 126 were from the Preschool Education Department; 63 were from the Classroom Teaching Department; 59 were from the Social Sciences Teaching Department; 72 were from the Turkish Education Department; 78 were from the Mathematic Teaching Department and 67 were from the Science Teaching Department. Following the analysis of the participant teachers' demographic features, it was concluded that $80.2 \%$ of the participants were female and $22.6 \%$ were male; $22.6 \%$ were at the age of 20 or younger; $38.7 \%$ were at the age of $21 ; 26.5 \%$ were at the age of $22 ; 12.3 \%$ were at the age of 23 and older. Additionally, $19.4 \%$ were found to have received assertiveness training before. In the light of the above, the study sample consisted of $4654^{\text {th }}$ year classroom teacher candidates attending Afyon Kocatepe University, Education Faculty. The data collection instruments of the study were the Personal Information Form designed to get information about the participant teacher candidates, the Voltan Acar Assertiveness Scale developed by Voltan Acar and Öğretmen (2007) and administered to assertiveness levels of the participant teacher candidates, and the Facial Expressions Form developed by Thayer and Schiff (1969) so as to specify the participant teacher candidates emotions and moods. The Personal Information Form which was developed by the researchers included multiple-choice questions regarding the participant teacher candidates' gender, age, department, high school type, family type, number of siblings, birth order, having received assertiveness training before or not and general communication skills. A 6- point Likert-type scale, 
The Voltan Acar Assertiveness Scale developed by Voltan Acar and Öğretmen (2007) is of two dimensions and 28 items. The original internal consistency reliability coefficient of the instrument was 0.78 for assertiveness dimension and 0.83 for avoidance dimension. The total internal consistency reliability coefficient of the instrument was 0.87 . For the current study, the measured internal consistency reliability coefficient of the instrument was 0.78 for assertiveness dimension and 0.81 for avoidance dimension; and the total internal consistency reliability coefficient was 0.85. Facial Expressions Form developed by Thayer and Schiff (1969) consists of the illustrations showing 11 different facial expressions.

Results: In terms of the participant teacher candidates' gender, there was no statistically significant difference in both Assertiveness and Passiveness sub dimensions and in total score of Voltan Acar Assertiveness Scale ( $p>.05$ ). In terms of age variable, the difference between Passiveness subdimension and total score was found to be statistically meaningful $\left(\mathrm{X}^{2}=9.039, p<.05\right)$ while it was found statistically significant in Assertiveness subdimension $\left(X^{2}=6.726, p>.05\right)$. The difference between Assertiveness subdimension $\left(X^{2}=21.384, p<.05\right)$ and total scores $\left(X^{2}=18.15, p<.05\right)$ were found statistically meaningful in terms of the participant teacher candidates' departments, no significant differences were found in Passiveness subdimension scores $\left(X^{2}=10.76\right.$, $\mathrm{p}>$.05). There were significant differences between Passiveness subdimension $\left(\mathrm{X}^{2}=7.956, p<.05\right)$ and total scores $\left(\mathrm{X}^{2}=7.307, p<.05\right)$ in terms of family type variable while it was not significant in Assertiveness subdimension scores $\left(X^{2}=3.183, p>.05\right)$. Considering birth order of the participants, it was concluded that there was no statistically significant difference between Assertiveness and Passiveness sub dimensions, and total scores ( $\mathrm{p}>.05$ ). To the perceived communication levels of the teacher candidates, statistically meaningful differences were found in Assertiveness subdimension $\left(\mathrm{X}^{2}=32.361, p<.05\right)$, Passiveness subdimension $\left(\mathrm{X}^{2}=28.124, p<.05\right)$ and total scores $\left(X^{2}=39.344, p<.05\right)$. In terms of teacher candidates' mood, similarly statistically significant differences were found in Voltan Acar Assertiveness Scale's Assertiveness $\left(\mathrm{X}^{2}=14.011, p<.05\right)$ and Passiveness $(\mathrm{F}=6.828, p<.01)$ sub dimensions and total scores $\left(\mathrm{X}^{2}=24.445, p<.05\right)$.

Discussion and Conclusion: The results and findings of the related studies in the literature are parallel with the findings of the current study. In their study examining the relationship between depression and assertiveness levels among nursing students, Rezayat \& Dehghan Nayeri (2014) concluded that gender was not a determinant in assertiveness level. Also, in their study examining the relationship between assertiveness levels and cultural sensitivity among nursing students, Parlar Kılıç ve Sevinç (2018) found that there was meaningful difference between assertiveness level and age. In his research aiming to reveal the assertiveness levels of the female students at Education Faculty, Yogaranee (2016) indicated that birth order was not effective in assertiveness level. And, in their study on university students' assertiveness levels, Haladin, Ibrahim, \& Rajab (2013) found a positive and linear relationship between students' assertiveness levels and communication skills. In his study that examined the relationships between assertiveness levels and social support perceptions and emotional well-beings of the teacher candidates attending to Psychological Counseling and 
Guidance Department, Ateş (2016) found that there was a positive and linear relationship between teacher candidates' assertiveness levels and emotional well-beings. 


\section{Kaynakça}

Adana, F. Aktaş, B., Erdağı, S., Eliş, S., Alkan, H. \& Uluman, Ö. (2009). Hemşirelik ve sağl1k memurluğu öğrencilerinin atılganlık düzeylerinin belirlenmesi. Atatürk Üniversitesi Hemşirelik Yüksekokulu Dergisi, 12(2), 51-56.

Akeren, İ. (2017). Üniversite ögrencilerinde algllanan sosyal destek ve güvengenlik ile psikolojik yardım ihtiyacının incelenmesi (Yayınlanmamış Yüksek Lisans Tezi). Atatürk Üniversitesi, Erzurum, Türkiye.

Alberti, R., \& Emmons, M. (1998). Atılganlık hakkınızı kullanın (S. Katlan, Çev.). Ankara: Hekimler Yayın Birliği.

Alberti, R., \& Emmons, M. (2002). Kendinize yatırım yapın! Atılganlık (S. Katlan, Çev.). Ankara: Hekimler Yayın Birliği.

Arslantaş, H., Adana, F., \& Şahbaz, M. (2013). Lise öğrencilerinin atılganlık düzeylerinin bazı değişkenler açısından incelenmesi. Florence Nigthingale Hemşirelik Dergisi, 21, 76-84.

Ateş, B. (2016). Perceived social support and assertiveness as a predictor of candidates psychological counselors' psychological well-being. International Education Studies, 9(5), 28-39.

Avcıoğlu, H. (2007). Sosyal becerileri değerlendirme ölçeğinin geçerlik ve güvenirlik çalışması (4-6 Yaş). Abant İzzet Baysal Üniversitesi Ĕ̈itim Fakültesi Dergisi, 7(2), 87-101.

Büyüköztürk, Ş., Kılıç, E., Akgün, Ö. E., Kardeniz, Ş., \& Demirel, F. (2009). Sosyal bilimlerde araştırma teknikleri. Ankara: Pegem Akademi Yayıncılık.

Caldarella, P., \& Merrell, K. W. (1997). Common dimensions of social skills of children and adolescents: A taxonomy of positive behaviors. School Psychology Review, 26(2), 264-278.

Dinçyürek, S., Çağlar, M., \& Birol, C. (2012). Atılganlık ve denetim odağı düzeyi: gelecek nesillere etkisi. Hacettepe Üniversitesi Eğitim Fakültesi Dergisi, 39, 142150 .

Dinçyürek, S., Güneyli, A., \& Çağlar, M. (2012). The relation between assertiveness levels, locus of control and academic success of Turkish language teacher candidates. Sociology Mind, 2(1), 61-66.

Eliason, C., \& Jenkins, L. (2003). A practical guide to early childhood curriculum. Upper Saddle River, N.J.: Merrill Press.

Eslami, A. A., Rabiei, L., Afzali, S. M., Hamidizadeh, S., \& Masoudi, R. (2016). The effectiveness of assertiveness training on the levels of stress, anxiety, and depression of high school students. Iran Red Crecent Journal Medical Journal, 18(1), 1-10.

Eskin, M. (2003). Self-reported assertiveness in Swedish and Turkish adolescents: A cross cultural comparison. Scandinavian Journal of Psychology, 44(1), 7-12. 
Gündoğdu, R. (2012). Yaratıcı drama temelli atılganlık programının psikolojik danışman adaylarının atılganlık becerisine etkisi. Kuram ve Uygulamada Eğitim Bilimleri, 12(2), 677-693.

Güneş, F., Arslan, C., \& Eliüşük, A. (2014). At1lganlık eğitiminin üniversite öğrencilerinin kişiler arası problem çözme, algılanan sosyal destek ve atılganlık düzeyleri üzerine etkisi. Bartın Üniversitesi Eğitim Fakültesi Dergisi, 3(1), 456474.

Güven, M. (2010). An analysis of the vocational education undergraduate students' levels of assertiveness and problem-solving skills. Procedia Social and Behavioral Sciences, 2(2), 2064-2070.

Haladin, B. N., Ibrahim, A. N., \& Rajab, A. (2013). Assertiveness among undergraduates in a Malaysian public university: Implications towards 1mproved employability. Jurnal Teknologi (Social Sciences), 65(2), 15-24.

Hamoud, S., Abd El Dayem, S., \& Ossman, L. (2011). The effect of an assertiveness training program on assertiveness skills and self-esteem of faculty nursing students. Journal of American Science, 7(12), 454-466.

Karagözoğlu, Ş., Kahve, E., Koç, Ö., \& Adamişoğlu, D. (2008). Self esteem and assertiveness of final year Turkish university students. Nurse Education Today, 28(5), 641-649.

Küçükkaragöz, H., Canbulat, T., \& Akay, Y. (2013). Öğretmen adaylarında atılganlık düzeyi ve iletişim becerileri. Mustafa Kemal Üniversitesi Sosyal Bilimler Enstitüsü Dergisi, 10(22), 123-133.

Maqbool Parray, W., \& Kumar, S. (2017). Impact of assertiveness training on the level of assertiveness, self-esteem, stress, psychological well-being and academic achievement of adolescents. Indian Journal of Health and Well-being, 8(12), 1476-1480.

Martínez, V., Justicia, F. Y., \& Haro, F. E. (2016). Teacher assertiveness in the development of students' social competence. Electronic Journal of Research in Educational Psychology, 14(2), 310-332.

Mayo Clinic Staff, (2012). Being assertive: Reduce stress, communicate better. Retrieved from https://www.mayoclinic.org/healthy-lifestyle/stressmanagement/indepth/assertive/art 20044644. Date of access: 10.03.2018.

Mılovanovıç, R., Irkovı Mıladınovıç, I., \& Stojanovı, B. (2016). Assertiveness of prospective teachers and preschool teachers. Journal Plus Education, 16(2016), 289-303.

Niusha, B., Farghadani, A., \& Safari, N. (2012). Effects of assertiveness training on test anxiety of girl students in first grade of guidance school. Procedia - Social and Behavioral Sciences, 46(2012), 1385-1389.

Parlar Kılıç, S., \& Sevinç, S. (2018). The relationship between cultural sensitivity and assertiveness in nursing students from Turkey. Journal of Transcultural Nursing, 29(4), 379-386. 
Rezayat, F., \& Dehghan Nayeri, N. (2014). The level of depression and assertiveness among nursing students. Journal of Commnunity Based Nursing and Midwifery, 2(3), 177- 184.

Rusli, K. A., Nasir, M. A. M., \& Hamzah, N. A. (2011). Relationship between interpersonal communication competence and students' assertive behaviour. Journal of Human Capital Development, 4(1), 25-33.

Shafiq, S., Naz, A. R. \& Yousaf, B. (2015). Gender differences between assertiveness and psychological well being among university students. Educational Research International, 4(2), 87-95.

Segrin, C. (2001). Social skills and negative life events: Testing the deficit stress generation hypothesis. Current Psychology, 1(20), 19-35.

Sucan, S., Turan, B. M., Pepe, O., Karaoğlu, B., \& Doğan, D. (2016). The relationship of assertiveness and locus of control with learning styles of the physical education and sports school students. International Journal of Science Culture and Sport, 4(Special Issue 1), 1-10.

Thayor, S., \& Schiff, W. (1969). Stimulus factors in observer judgment of social interaction: Facial expression and motion pattern. The American Journal of Psychology, 82(1), 73-85.

Twenge, J. M. (2001). Changes in women's assertiveness in response to status and roles: A cross-temporal meta-analysis, 1931- 1993. Journal of Personality and Social Psychology, 81(1), 133-145.

Uğurluoğlu, M. Y. (1996). Lise öğrencilerinde özsaygı düzeyi ile atılgan kişilik özelliği arasındaki ilişkinin incelenmesi (Yayımlanmamış Yüksek Lisans Tezi). Karadeniz Teknik Üniversitesi Sosyal Bilimler Enstitüsü, Trabzon.

Unal, S. (2012). Evaluation the effect of self-awareness and communication techniques on nurses' assertiveness and self-esteem. Contemporary Nurse, 43(1), 90-98.

Uzuntarla, Y., Uğrak, U., \& Cihangiroğlu, N. (2016). Sürekli kayg1 ve atılganlık arasındaki ilişkinin incelenmesi. Uluslararası Sosyal Araştırmalar Dergisi, 9(42), 1704-1711.

Vagos, P., \& Pereira, A. (2010). A proposal for evaluating cognition in assertiveness. Psychological Assessment, 22, 657-665.

Vatankhah, H., Daryabari, D., Ghadami, V., \& Naderifar, N. (2013). The effectiveness of communication skills training on self-concept, self-esteem and assertiveness of female students in guidance school in Rasht. Procedia-Social and Behavioral Sciences, 84(2013), 885-889.

Voltan, N (1980). Grupla atılganlık eğitiminin bireyin atılganlık düzeyine etkisi (Yayınlanmamış Doktora Tezi). Hacettepe Üniversitesi, Ankara, Türkiye.

Voltan, N. (1995). Psikolojik danışmada çeviri sorunu. Bilim ve Ütopya Dergisi, 14, 28 29. 
Voltan Acar, N., \& Öğretmen, T. (2007). Kendini belirleme (güvengenlik) ölçeği geliştirme çalışmaları. Türk Psikolojik Danışma ve Rehberlik Dergisi, 3(27), 67-78.

Voltan Acar, N., Arıcıoğlu, A., Gültekin, F., \& Gençtanırım, D. (2008). Üniversite öğrencilerinin güvengenlik düzeylerinin incelenmesi. Hacettepe Üniversitesi Ĕ̈itim Fakültesi Dergisi, 35, 342-350.

Yamada, K., Maeuezato, N., \& Ohtsu, K. (2013). Effective teaching learning process for training assertive communication skills. School Health, 9, 45-58.

Yogarenee, S. (2016). Factors 1nfluencing assertiveness of prospective teachers of the university of Colombo, Sri Lanka. Research Journal of Recent Sciences, 5, 95-99.

Yüksel, G. (2001). Öğretmenlerin sahip olmaları gereken davranış olarak sosyal beceri.
Milli Ĕ̈itim
Dergisi,
Mart,
Nisan,
Mayis.

https://dhgm.meb.gov.tr/yayimlar/dergiler/Milli_Egitim_Dergisi/150/yuksel.htm sitesinden alınmıştır. Erişim tarihi: 16.03.2018. 